\title{
Mainstreaming emergency contraception pills in Kenya
}

\author{
Jill Keesbury \\ Population Council \\ Monica Wanjiru \\ Population Council \\ Katherine Maina
}

Follow this and additional works at: https://knowledgecommons.popcouncil.org/departments_sbsr-rh

Part of the Community Health Commons, Health Policy Commons, International Public Health Commons, Obstetrics and Gynecology Commons, Public Health Education and Promotion Commons, and the Women's Health Commons

How does access to this work benefit you? Let us know!

\section{Recommended Citation}

Keesbury, Jill, Monica Wanjiru, and Katherine Maina. 2010. "Mainstreaming emergency contraception pills in Kenya," policy brief. Nairobi: Population Council. 


\section{Mainstreaming Emergency Contraception Pills in Kenya}

\section{Introduction}

7 mergency contraception (EC) is an important element of reproductive

healthcare. EC is the only family planning method that can be used to prevent pregnancy after rape or unprotected sex. It does not cause abortion or harm to an existing pregnancy.

According to the 2003 Kenya Demographic Health Survey (KDHS), close to half of the births in the preceding 5 years were mistimed or unwanted. The preliminary results of the 2008 KDHS indicate that less than half $(46 \%)$ of currently married women were using some method of contraception; use was lowest among women between the ages of 15 and 24. Increased access to family planning, including EC, can reduce the number of unplanned pregnancies in the country and contribute to lower rates of abortion, child neglect, and abandonment.

"I think we have not adequately explained to the community that the morning-after pill should be used only in situations where people have accidentally had unprotected sex or in the case of sexual coercion."

- Dr. Shahnaaz Sharif, Director, Public Health and Sanitation, MOPHS

Despite increased media attention, EC remains a highly underutilized method across Kenya. Recent data indicate that only $56 \%$ of women of reproductive age had ever heard of EC. ${ }^{1}$ To improve access to the method and ensure that adequate information is provided to all users, the Ministry of Public Health and Sanitation (MOPHS), Population Council, Population Services International- Kenya (PSI) undertook a 3-year effort to mainstream EC in Kenya, which was supported by the William and Flora Hewlett Foundation. This brief presents the results of this initiative, and discusses strategies for further strengthening EC provision in Kenya. 


\section{What is EC?}

"Emergency contraception" refers to the use of certain contraceptive methods by women and girls to prevent pregnancy after unprotected sexual intercourse. These methods include specific dedicated products (such as the brands Postinor-2 and Pregnon) and higher doses of other hormonal birth control pills (known as the Yuzpe method). EC is recommended for women who have had unprotected sexual intercourse and desire to prevent pregnancy. In Kenya, dedicated EC pills

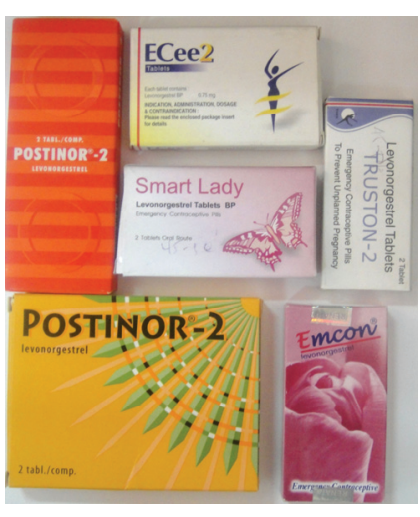
(ECPs), are available in the public family planning clinics and as a part of post-rape care services; they are also widely found in Kenya's private sector pharmacies and clinics.

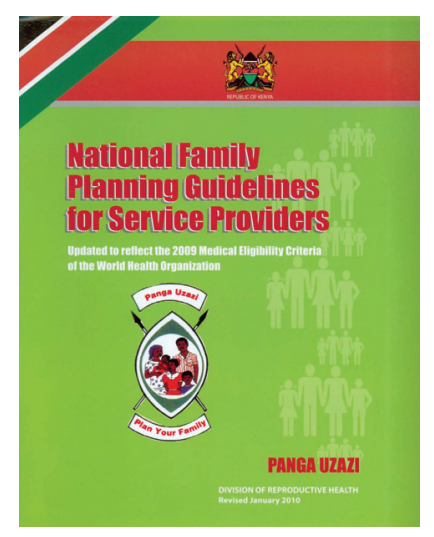

The Kenyan National Family Planning Guidelines recommend use of ECPs within 120 hours for women who have had unprotected sexual intercourse and desire to prevent pregnancy. ${ }^{2} \mathrm{EC}$ is the only contraceptive method that provides women with a second chance for preventing pregnancy after unprotected sex. ECPs do not cause abortion or harm an existing pregnancy, and are widely recognized as safe and easy to use. Any woman of reproductive age can use ECPs. While most women do not experience side effects, the most common side effects, including nausea, vomiting, and headaches, usually disappear within 24 hours. ECPs work by either inhibiting or delaying ovulation or preventing fertilization, depending on the time it is taken during the cycle.

Dedicated ECPs are effective in preventing up to $95 \%$ of pregnancies, and the Yuzpe method is effective in approximately 75$80 \%$ of cases; the efficacy of ECPs is greater if taken as soon as possible after unprotected sex.

Visit the following websites for more information on EC:

- ECafrique: The African Forum on Emergency Contraception; www.ecafrique.org

- The International Consortium on Emergency Contraception; www.emergencycontraception.org

- Not-2-late.com http://ec.princeton.edu/

- The Latin American Consortium on Emergency Contraception (in Spanish); www.clae.info 


\section{The initiative to mainstream ECPs in Kenya}

In 2006, the Population Council and PSI launched an initiative to support the MOPHS' efforts to strengthen ECP provision in the public and private sectors. Activities included a national awareness-raising campaign, technical assistance to the Division of Reproductive Health (DRH) to build capacity and ensure supply sustainability, and efforts to improve ECP services in private sector pharmacies.

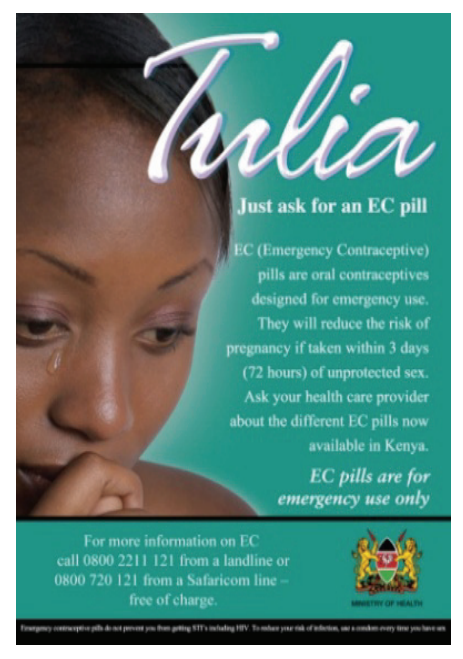

Awareness-raising campaign: A national mass- media campaign, branded Tulia ("relax" in Kiswahili) was undertaken to increase public awareness of ECPs. It included national and local-language radio spots, informational articles in print media, expert interviews on radio and TV, and EC messages presented through popular local soap operas. PSI also developed brochures answering clients' key questions and concerns regarding ECP use, which were distributed through pharmacies and private clinics.

To encourage bridging client from ECPs to regular family planning methods, PSI organized community-level events, such as discussion groups and career fairs, that provided women aged 18-30 with information on ECPs and other regular family planning methods. All Tulia materials contained contact information for a youth reproductive health $(\mathrm{RH})$ hotline run by Liverpool VCT, Care and Treatment. All hotline staff were trained to provide information and counseling to women with questions about EC.

\section{Public sector capacity building: A study carried} out by the Population Council in 2007 found that, while $96 \%$ of FP providers had heard of EC, only $56 \%$ had ever been trained to provide ECPs and far fewer demonstrated adequate knowledge of the method. Guided by these findings, the DRH increased efforts to train FP providers on ECPs through contraceptive technology updates. Partners from the USAIDfunded national AIDS, Population and Health Integrated Assistance (APHIA II) Project, which reaches providers across the country, were also

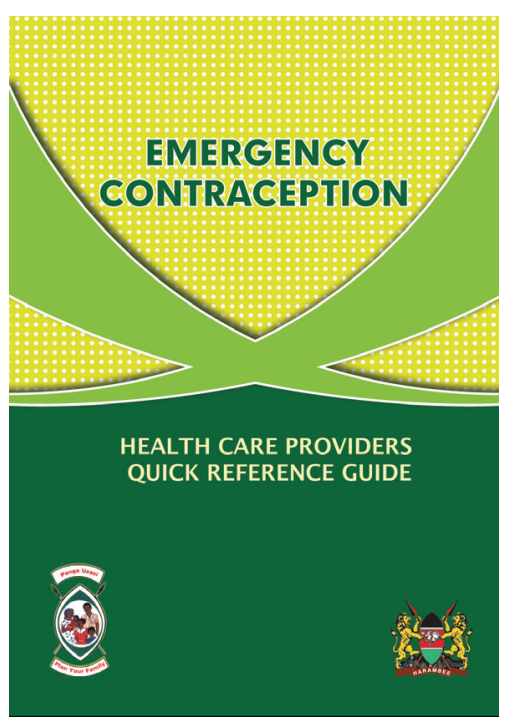


encouraged to emphasize the method in their trainings. Through these efforts, over 2,000 providers received in-service training on ECPs between 2007 and 2008. A quick reference guide and job-aid were also developed for providers, and the 2010 revision of the National Family Planning Guidelines includes significantly strengthened guidance on ECPs.

The government also took steps to strengthen pre-service training as a sustainable and cost-effective approach to improving provider competence. With technical assistance from the Population Council, the Nursing Council of Kenya revised its syllabus to include training on ECPs for student nurses. Efforts are currently underway to integrate EC into the Kenya Medical Training Colleges' curriculum.

Supply sustainability: To improve record-keeping and allow facilities to reorder ECPs, in 2008 the DRH added a column for ECPs to the revised FP register. The MOPHS also included purchase of ECPs in its budget, and in 2009, procured 5,875,000 ECPs with its own funding

\section{Strengthened pharmacy services: The Population Council worked in} collaboration with the Pharmaceutical Society of Kenya to address concerns of private providers regarding EC provision, and test strategies for improving ECP services in the pharmacies. The Council conducted an intervention study which worked to enhance the capacity of private pharmacy providers to provide quality ECP services. The study was conducted in 20 Nairobi pharmacies and included three components: detailing providers on the appropriate use of ECPs and how best to dispense ECP to clients; ensuring the availability of Tulia brochures and posters in participating pharmacies, and providing "cheat sheets" containing five simple messages on ECPs to display at the counter. The intervention also aimed to limit repeat use by "bridging" current users to other RH services, including VCT and

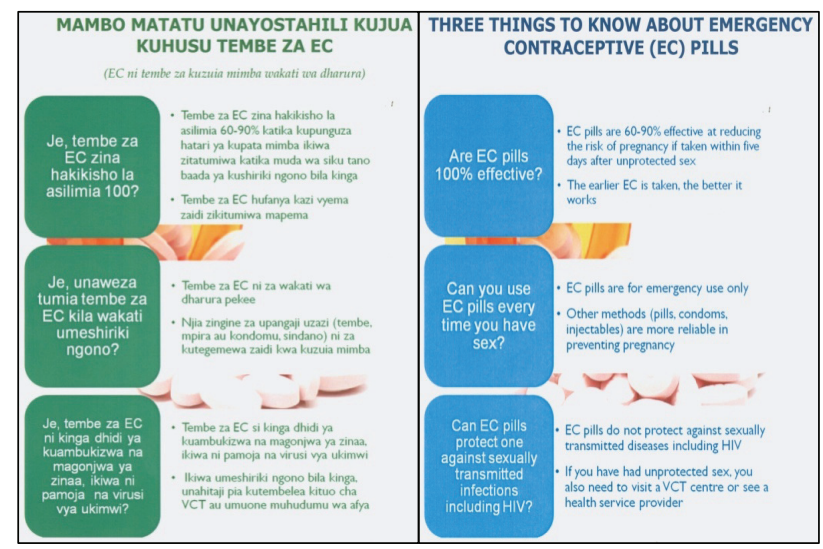

'Cheat' sheets with the key messages on EC (English and Kiswahili versions) longer-term FP. 


\section{Lessons learned on ECP provision in Kenya}

The initiative has helped improve understanding of the dynamics of ECP provision in Kenya, increased access to the method in the public and private sectors, and developed innovative and cost-effective strategies for providing basic information to users. The key lessons learned are summarized below.

\section{Awareness and use of ECPs has increased dramatically in Kenya, but still remains low}

Awareness and reported use of ECP increased dramatically over the life of the initiative. In 2003, the KDHS indicated that less than one quarter of Kenyan women had ever heard of

ECPs. ${ }^{3}$ In 2007, PSI conducted baseline research in 13 major towns and peri-urban areas across 7 provinces, and found similar patterns, with only $21 \%$ of women reporting having ever heard of

\begin{tabular}{|l|c|c|c|}
\hline Source & Year & $\begin{array}{c}\text { Ever heard of } \\
\text { EC (women) }\end{array}$ & $\begin{array}{c}\text { Ever } \\
\text { use }\end{array}$ \\
\hline DHS & 2003 & $24 \%$ & $0.9 \%$ \\
\hline PSI baseline $(n=675)$ & 2007 & $24 \%$ & $5 \%$ \\
\hline PSI endline $(n=1252)$ & 2009 & $56 \% *$ & $10 \% *$ \\
\hline
\end{tabular}

$* p=<0.05$, comparing 2007 to 2009 results

Table I: Knowledge and use of EC in Kenya, DHS and PSI baseline surveys ECPs. Of those, only $15 \%$ could correctly identify ECPs as a contraceptive method taken after sex to prevent pregnancy. ${ }^{4}$ By $2009,56 \%$ of women in the same sites had ever heard of ECP and $10 \%$ had ever used the method. 5

ECP sales data, obtained from the major ECP distributors in Kenya, also demonstrates an increased demand for the method. Figure 1 charts the dramatic growth in ECP sales by distributors over a 22 month period. During that time, the number of ECP brands on the market increased from 3 to 4 , indicating a robust demand for the method. Similar trends are seen in the public sector, although the volumes are

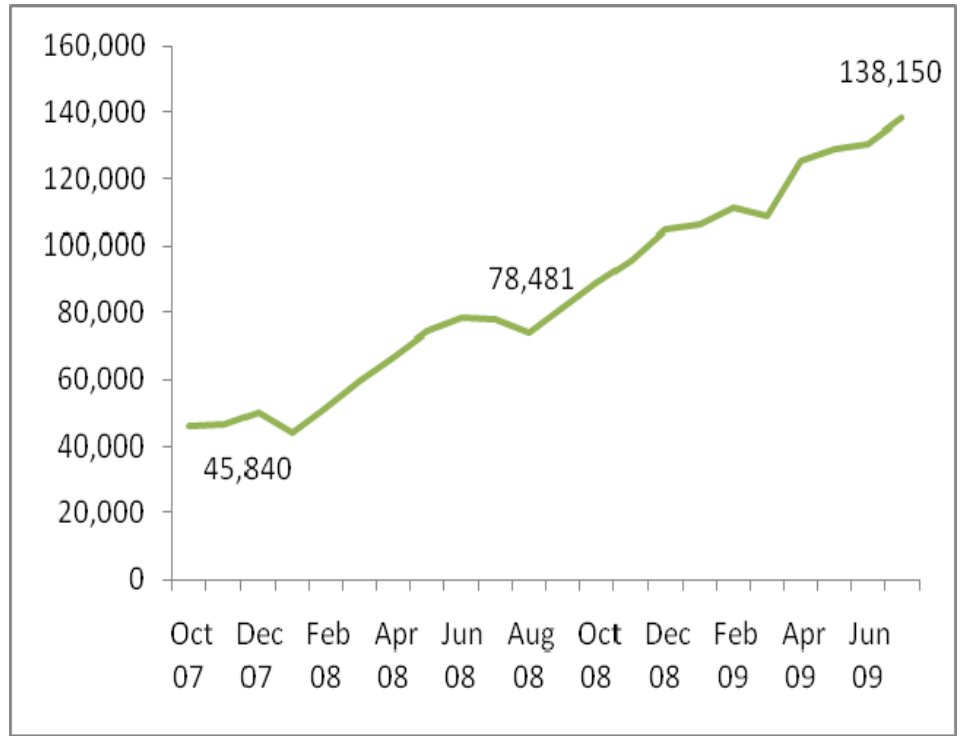

Figure I: National sales of ECPs vs. public sector issues, 2008 significantly lower. ${ }^{6}$ 
However, PSI's endline survey indicates that $44 \%$ of all eligible women are still not aware that ECP exists, and misconceptions are rife among those who do know about the method. Of all women who know of ECPs, one-third believes that it causes abortion, and only about two-thirds know the correct timeframe for using the method. This indicates the need for continued education and awareness-creation on ECPs.

\section{Private sector pharmacies dominate ECP provision in Kenya}

Data collected under the initiative demonstrates that private sector pharmacies are the most common access point for ECPs. PSI's 2007 baseline survey found that $94 \%$ of women who had used ECP in the past two years obtained it from pharmacies. ${ }^{7}$ In 2009 , their endline survey found that while $83 \%$ identified pharmacies as a place to obtain ECPs, only $25 \%$ mentioned government clinics. ${ }^{8}$

In 2008, as indicated in Figure 2, national-level ECP distribution through private sector pharmacies was approximately twice that distributed through the public sector.

Within government clinics, a 2007 record review found that $93 \%$ of the ECPs distributed in the previous 18

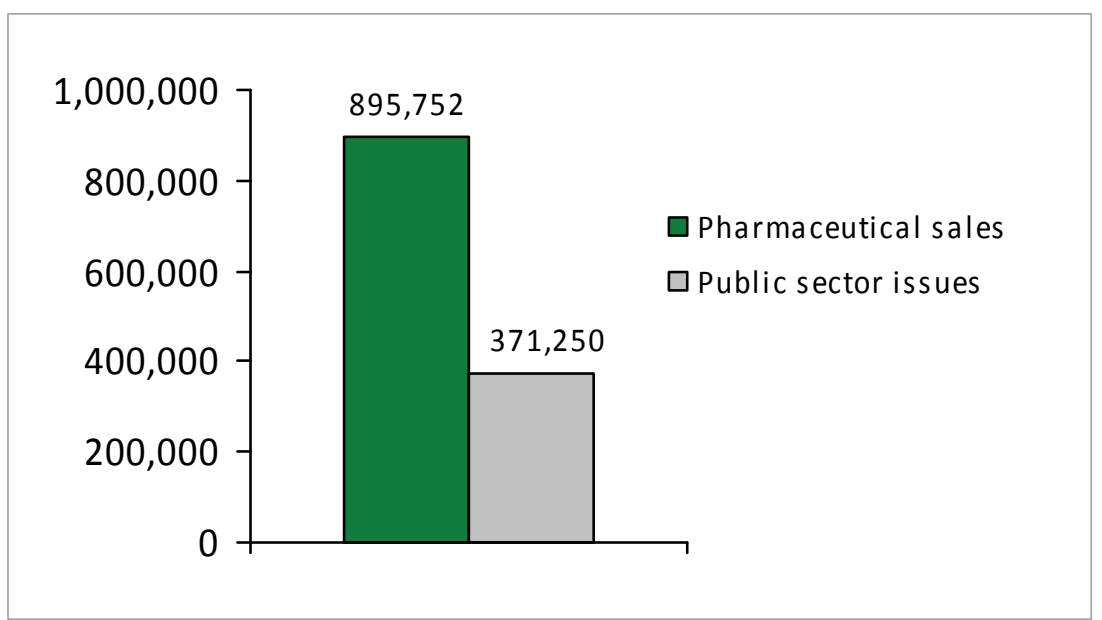

Figure 2: National Sales of 4 ECP brands, over project life months were for sexual assault cases. While efforts under this initiative worked to strengthen ECP provision within FP and ARH services, it is likely that a bias towards sexual assault provision still exists within many public health facilities. ${ }^{9}$

Qualitative research conducted with ECP users indicated that they preferred to access ECPs through pharmacies because it was convenient, quick and confidential. ${ }^{10}$ Two-thirds of women who purchased ECPs indicated that they had visited more than one pharmacy in an effort to maintain anonymity. ${ }^{11}$

These findings suggest that the challenge in delivering quality ECP services within pharmacies lies with balancing efforts to provide basic information on the method without compromising the qualities that make pharmacies so attractive to clients. Within the public sector, the challenge rests with increasing the speed and confidentiality of ECP services within the context of larger FP programs. 
The majority of women who purchase ECPs from pharmacies are educated and employed

Media reports have characterized ECP users, especially those who access EC from pharmacies, as "girls as young as 14." 12 Research conducted under this initiative, however, indicates this is not the case. In 2007, the Population Council conducted a client intercept study (where clients are interviewed after receiving a service) with 147 women who bought ECPs at pharmacies in urban pharmacies located in five provinces (Nairobi, Coast, Rift Valley, Nyanza and Western).

The results show that the average age of women surveyed was 25 years, and the majority was between $20-29$ years (72\%). None of these women reported that they were aged 14 or below, and only $11 \%$ of respondents were between the ages of 15-19. Most clients had a college/university level of education $(61 \%)$ and $61 \%$ were currently employed (including self-employment). About two-thirds $(65 \%)$ were either married/cohabiting or single but in a steady relationship, but most women (57\%) also reported engaging in sex on an infrequent or irregular basis. A significant proportion (41\%) reported having at least one child. ${ }^{13}$

\section{Some Kenyan women have used ECPs more than once in a month, but repeat users are less informed about the method}

Respondents in the 2007 client intercept study were asked about the number of times they had used ECPs in the past six months, frequency of use in relation to sexual activity, and time since last purchase of ECPs. The categorization of "repeat use" is based on the last question, and is defined as a client who has bought ECPs at least once previously in the past one month.

Data indicate that a majority (58\%) of women who had purchased ECPs had done so two or more times in the last month. Most of these purchasers (74\%) stated that they used ECPs as their only method during their last act of sex, and nearly as many $(70 \%)$ thought that ECPs were more convenient than other methods, while almost half preferred ECPs over methods such as daily contraceptive pills or injectables.

While repeat use of ECPs may be a conscious decision, it is not necessarily an informed one. The data also demonstrate that women who repeatedly used ECPs had greater misperceptions about the method's mechanism of action and efficacy. Nearly 60 percent believed that ECPs are $100 \%$ effective, and many incorrectly believed that it would cause infertility or abortion.

Overconfidence in $\mathrm{ECP}^{\prime}$ s efficacy is likely to be one factor underpinning repeat use, with the benefits of convenience in the short-term outweighing perceived long-term consequences. ${ }^{14}$ 
It is important to note that no significant negative health consequences have been associated with repeat use of ECP. ${ }^{15}$ Current national and international guidelines, however, do not encourage reliance on EC as a regular method of FP. According to the World Health Organization, recurrent use of EC indicates the need for further counseling on contraceptive options. ${ }^{16}$ No conclusive evidence is available on the efficacy of ECPs if taken more than once in a cycle.

\section{Pharmacies can provide better ECP services with minimal investment}

Given the key role pharmacies currently occupy in the provision of ECP in Kenya, and the demonstrated need for better client counseling, innovative efforts are needed to improve EC services within pharmacies.

The strategy for providing basic information to pharmacy clients tested under this initiative demonstrated promising results. Results of this intervention indicated that, when given basic information, pharmacy staff were more likely to provide basic information on ECPs (including when and how to use, mechanism of action, side effects and efficacy) and discuss other FP and RH services with clients. These results suggest that sales staff at private sector pharmacies can deliver better ECP services, if given the proper tools. It also indicates that extensive, and often costly, training efforts are not needed to improve services within pharmacies. ${ }^{17}$

\section{Integrating skills and knowledge on ECPs into existing pre-service and in-service training programs can enhance public sector provision}

Under the initiative, efforts focused on integrating EC into existing pre- and in-service training programs in a cost-effective and sustainable manner. With minimal resources, modules on ECPs were inserted into ongoing trainings conducted by APHIA II partners and in the regular MOPHS Contraceptive Technology Updates (CTUs); evaluation data showed increased knowledge among trained providers. Perhaps the most strategic investment was in preservice training, where limited technical and financial support enabled the integration of EC into the revised Nursing Council's curriculum, ensuring that all future nurses will receive instruction on ECPs.

These experiences demonstrate that existing FP and RH initiatives can be successfully used to promote knowledge on ECPs. They also underscore the utility of integrating EC into existing activities, which is more-cost effective than stand-alone trainings and promotes the principle that EC should be addressed in the context of comprehensive FP and post-rape care services. 
Active advocacy is necessary to ensure adequate ECP stocks in the public sector.

Supply sustainability of all contraceptives, especially ECPs, remain a major challenge for the Kenyan government. Continued or sustained stock-outs would undermine the gains made during this initiative, and limit the impact of the policy and program changes that have been undertaken in recent years. As knowledge of ECPs increase throughout the country, so will supply requirements, and efforts to ensure sufficient commodities should continue.

Under the leadership of the DRH, advocacy efforts ensured that ECPs were included in the national contraceptive security plan and subsequent procurements. Since 2005, UNFPA has donated approximately 1,100,000 units to the MOPHS. In 2009, the MOPHS committed its own funds to purchase the country's largest procurement of ECPs to date of 5,875,000 units.

\section{Recommendations}

The following recommendations are based on the lessons learned under this initiative.

1. Efforts to create public awareness and correct knowledge of ECPs should be continued. While knowledge of ECPs is increasing in Kenya, many potential beneficiaries are still unaware of the method and many others are misinformed. Accurate public information and education is critical for encouraging correct use of ECPs. It is important, therefore, to include messages on ECPs in comprehensive FP communication campaigns. This can be achieved by integrating the existing Tulia materials and messages into the national $\mathrm{RH}$ communication strategy operational plan, and in the DRH's community education and communication activities. The media can also play a critical role in creating correct public perceptions of the method, and should be regarded as a partner in these activities.

2. Professional associations, including the Pharmaceutical Society of Kenya and the Kenya Pharmaceutical Association, should continue educating their members on proper ECP provision. Given the central role pharmacies play in ECP access in Kenya, professional associations should work to ensure that their members are aware of strategies for ensuring clients are provided with the information they need to make informed decisions on ECP use. Such strategies need not be costly or time-intensive; this initiative demonstrated one model for increasing information provision in pharmacies, and others are likely to be feasible. At a minimum, the professional associations should include informational sessions and discussions on ECPs at all general meetings. 
3. All MOPHS training partners should ensure that ECPS are integrated into all trainings on FP, RH, adolescent health or post-rape care. Numerous local and international NGOs assist the MOPHS with provider training. These partners' contributions can also be used to increase knowledge on ECPs, with as little as two additional hours of instruction for trained health care providers. The DRH should integrate existing training materials and job aids into a standardized module on ECPs to ensure that all partners offer uniform, high-quality instruction.

4. All pre-service training institutions and bodies should include ECP provision in their curricula and examinations. Pre-service training is necessary to ensure that the next generation of Kenya's health professionals are well-equipped to provide this important and increasingly popular method. To do this, the country's leading medical pre-service training institutions must revise their curricula to reflect the MOPHS' renewed emphasis on quality ECP provision.

5. The MOPHS, donors and partners should continue to ensure that adequate ECP supplies are available in the public sector. Adequate stocks are essential in ensuring the success of public sector ECP provision. Remarkable progress towards this has been achieved through the inclusion of ECP in the government's FP commodities procurement and security plans. It is recommended that donors and other MOPHS partners continue to support the government to ensure that this emphasis on stock sustainability is maintained. Donors can also encourage their partners to integrate ECP issues in their reproductive health communications, service delivery, logistics, trainings and research programs, and to explore innovative ways to strengthen private sector provision.

\section{Conclusion}

Kenya has emerged as a leader in EC programming in the region. Through this initiative, it has demonstrated that it is possible to strengthen ECP services in both the public and private sectors while at the same time increasing public awareness, knowledge and use of the method.

The Kenyan experience can serve as a model for other countries on the continent interested in mainstreaming ECP services. While Kenya may have a longer history with the method than other African countries, ECPs are rapidly becoming widely available in African pharmacies due to the aggressive expansion of new products. Countries such as Uganda, Botswana, Ghana, Nigeria and Malawi and Senegal are beginning to grapple with increased access in the private sectors, while many other governments are now more widely providing ECPs as a core element of post-rape care. The lessons learned from Kenya can serve as an invaluable resource to these countries. 


\section{References}

1 Population Services International- Kenya. Mainstreaming Emergency Contraception in Kenya: Final Narrative Report. October 2009. Unpublished report.

2 Kenya Ministry of Public Health and Sanitation, Division of Reproductive Health. National Family Planning Guidelines for Service Providers. 2010 Revision. Nairobi: Kenya.

${ }^{3}$ Central Bureau of Statistics (CBS) et al. Kenya Demographic and Health Survey 2003. 2004. Calverton, Maryland: CBS et al.

${ }^{4}$ Population Services International-Kenya. TRaC Summary Report: Baseline Study on EC Use among Urban and Peri-Urban Kenyan Women. 2007. Unpublished report.

${ }^{5}$ Population Services International- Kenya. Mainstreaming Emergency Contraception in Kenya: Final Narrative Report. October 2009. Unpublished report.

${ }^{6}$ Keesbury J, Liambila et al. Mainstreaming Emergency Contraception in Kenya : Final Project Report. 2009. Population Council: Nairobi.

7 Population Services International-Kenya. TRaC Summary Report: Baseline Study on EC Use among Urban and Peri-Urban Kenyan Women. 2007. Unpublished report.

8 Population Services International- Kenya. Mainstreaming Emergency Contraception in Kenya: Final Narrative Report. October 2009. Unpublished report.

${ }^{9}$ Keesbury J, Owino B and Bradford S. Emergency Contraception, Female Condoms and IUDs in Kenya's Public Sector: Findings from a National Diagnostic Assessment. 2007. Population Council: Nairobi.

10 Population Services International-Kenya. TRaC Summary Report: Baseline Study on EC Use among Urban and Peri-Urban Kenyan Women. 2007. Unpublished report.

11 Benter Owino and Jill Keesbury. Who uses Emergency Contraceptives? A profile of EC Users from Urban pharmacies in Kenya. 2007. Population Council: Nairobi.

12 Wesangula D. Scandal of birth pills for teenagers. Daily Nation, Nairobi: Kenya; 7 September 2008; 5-6.

${ }^{13}$ Keesbury J, Morgan G, Owino B. Is repeat use of emergency contraception common among pharmacy clients? Evidence from Kenya. Manuscript under review. 
${ }^{14}$ Keesbury J, Morgan G, Owino B. Is repeat use of emergency contraception common among pharmacy clients? Evidence from Kenya. Manuscript under review.

15 United Nations Development Program/ United Nations Population Fund/ World Health Organization/ World Bank Special Programme on Research, Development and Research Training on Human Reproduction. Task Force on Post-Ovulatory Methods of Fertility Regulation. Efficacy and side effects of immediate postcoital levonorgestrel used repeatedly for contraception. Contraception 2000; 61:303-8.

${ }^{16}$ World Health Organization. Medical eligibility criteria for contraceptive use, Third edition. Geneva: World Health Organization, 2004.

17 Obare F, Keesbury J, Liambila W. 2009. Bridging users of emergency contraceptives to other family planning and reproductive health services through private sector pharmacies in Nairobi, Kenya. Population Council: Nairobi.

This brief was prepared by Jill Keesbury, Monica Wanjiru and Katherine Maina. Please contact ecafrique@popcouncil.org for more information. 